\title{
Changes in antigen-specific T-cell number and function during oral desensitization in cow's milk allergy enabled with omalizumab
}

\author{
D Bedoret ${ }^{1}$, AK Singh $^{2}$, V Shaw ${ }^{1}$, EG Hoyte $^{2}$, R Hamilton $^{3}$, RH DeKruyff ${ }^{1}$, LC Schneider $^{1}$, KC Nadeau $^{2,4}$ \\ and DT Umetsu ${ }^{1,4}$
}

Food allergy is a major public health problem, for which there is no effective treatment. We examined the immunological changes that occurred in a group of children with significant cow's milk allergy undergoing a novel and rapid high-dose oral desensitization protocol enabled by treatment with omalizumab (anti-immunoglobulin (Ig)E monoclonal antibodies). Within a week of treatment, the CD4 + T-cell response to milk was nearly eliminated, suggesting anergy in, or deletion of, milk-specific CD4 + T cells. Over the following 3 months while the subjects remained on high doses of daily oral milk, the CD4 + T-cell response returned, characterized by a shift from interleukin- 4 to interferon- $\gamma$ production. Desensitization was also associated with reduction in milk-specific IgE and a 15-fold increase in milk-specific lgG4. These studies suggest that high-dose oral allergen desensitization may be associated with deletion of allergen-specific T cells, without the apparent development of allergen-specific Foxp3+ regulatory T cells.

\section{INTRODUCTION}

Although allergen desensitization in patients allergic to environmental agents, such as pollens, dust mite, or cat dander, has been performed for more than 100 years, ${ }^{1}$ the precise immunological mechanisms of allergen desensitization remain controversial. The development of blocking immunoglobulin (Ig)G antibody was initially thought to have an important role in mediating the allergen desensitization and tolerance processes. ${ }^{2}$ However, other mechanisms such as immune suppression, mediated by allergen-specific adaptive regulatory $\mathrm{T}\left(\mathrm{T}_{\mathrm{Reg}}\right)$ cells, have received intense investigation as the cell type that accounts for the success of immunotherapy. ${ }^{3-6}$ The development of allergen-specific Foxp $3^{+} \mathrm{T}_{\text {Reg }}$ cells during desensitization with inhalant allergen or bee venom is consistent with the idea that tolerance induced with low-antigen doses (microgram amounts), such as those used in subcutaneous desensitization protocols, is associated with the development of allergen-specific $\mathrm{T}_{\text {Reg }}$ cells. ${ }^{7}$

Protocols for oral allergen desensitization in patients with IgEmediated food allergy are currently being developed, but little is known about the mechanisms of oral desensitization, during which high doses (gram amounts) of oral antigen are generally administered. In mouse models of oral tolerance, administration of high doses of oral antigen in naïve animals is associated with the development of anergy and deletion of antigen-specific $\mathrm{T}$ cells, whereas administration of low doses of oral antigen is associated with $\mathrm{T}_{\mathrm{Reg}}$ cell development. ${ }^{8}$ On the other hand, much less is known about the mechanisms of oral desensitization in the setting of established allergy in humans.

In humans, the examination of the immunological mechanisms of oral desensitization for food allergy has been hampered by several problems. First, unpredictable allergic reactions in patients have resulted in desensitization courses that vary from months to years. In addition, food-specific T cells, which constitute a very small fraction $(<1 \%)$ of peripheral $\mathrm{T}$ cells, are difficult to study, and have been examined primarily via bulk population activation, or by cloning (or establishing cell lines), which typically involves several cycles of antigen stimulation with exogenous cytokines, ${ }^{9-11}$ although in some studies, peanut-specific $\mathrm{T}$ cells were examined more directly using a dye dilution method. ${ }^{12,13}$ Nevertheless, studies of oral food desensitization consistently demonstrate a decrease in allergenspecific IgE and an increase in allergen-specific IgG4, suggesting that oral desensitization induces allergen-specific immune deviation. ${ }^{14-18}$ 
To better understand the immunological changes that occur during oral food desensitization, we examined a small cohort of children with IgE-mediated milk allergy in a clinical trial of oral cow's milk desensitization performed in combination with a 16-week course of omalizumab (anti-IgE monoclonal antibodies (mAb), Xolair). The oral desensitization protocol, which was the first to use omalizumab to limit allergic reactions, allowed patients to be rapidly (over a 7- to 11-week period of time) desensitized to high doses of milk with a uniform dosing schedule. The clinical findings of this study, showing that 10 of the 11 patients with significant milk allergy were desensitized, have been briefly described elsewhere. ${ }^{19}$ Herein, we describe the dynamic milk-specific immunological changes that occurred in these patients, analyzed in several subgroups of patients, over the course of the oral milk desensitization protocol.

\section{RESULTS}

All subjects in the clinical trial began treatment with omalizumab at week 0 , and started oral desensitization with milk at week $9 .{ }^{19}$ Twelve doses of milk were given on the first day of desensitization, increasing from 0.1 to $1,000 \mathrm{mg}$ every $30 \mathrm{~min}$ (cumulative dose on the first day, 2,000 $\mathrm{mg}$ milk protein). The patients then continued on a daily dose of milk $(1,000 \mathrm{mg}$ per day), which increased every 7 days until a dose of 2,000 mg milk per day was achieved. At week 16, the omalizumab was discontinued, but patients remained on a daily dose $(2,000 \mathrm{mg}$ per day) of milk. At week 24, 9 of the 10 patients remaining in the study passed a double blind food challenge and began taking $>8,000 \mathrm{mg}$ of milk per day.

\section{Milk-induced CD4 T cell proliferation is reduced during rush desensitization}

Peripheral blood mononuclear cells (PBMCs) from a subset of five patients were isolated at multiple time points during the desensitization protocol (weeks $0,9,10,12,14,16,24,30$, 36 , and 52), and frozen in aliquots in liquid nitrogen for later examination. To characterize the response to milk, PBMCs from multiple time points for each patient were thawed, labeled with carboxyfluorescein succinimidyl ester (CFSE) and cultured in the presence of milk proteins (MPs) (or tetanus toxoid (TT)) for 7 days. In all patients examined, there was a vigorous proliferative response to MPs (and TT) at week 0 , as demonstrated by flow cytometry, which showed a significant number of CD4 ${ }^{+}$ $\mathrm{T}$ cells with low levels of CFSE, representing cells that underwent multiple cell divisions (Figure 1a; mean milk-specific CD $4^{+}$ $\mathrm{T}$ cells $=7.75 \%$; mean tetanus- specific cells $=24.6 \%$; mean, no
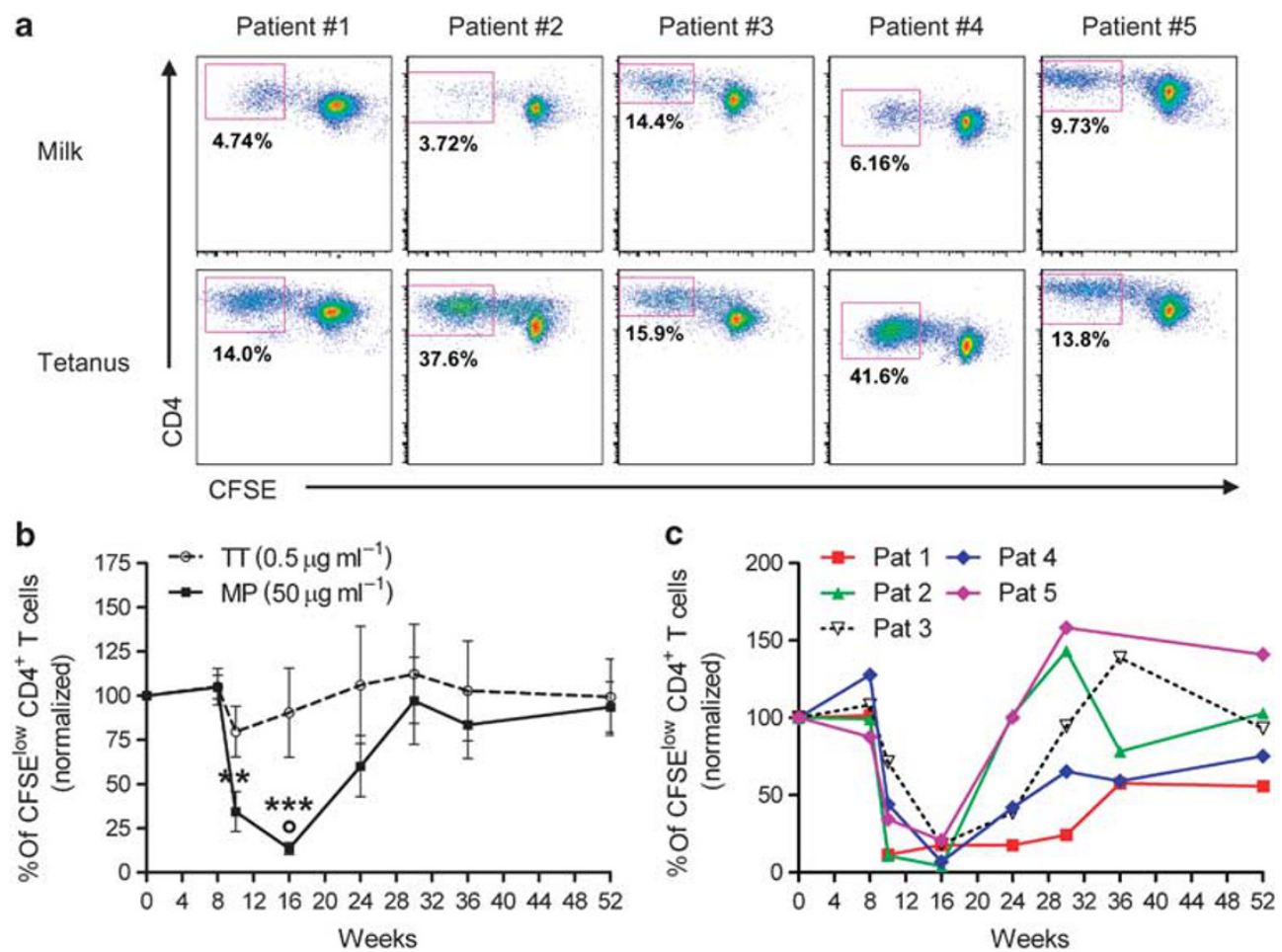

Figure 1 Milk-induced CD4+ T-cell proliferation is greatly reduced during the rush desensitization phase. (a) Frozen peripheral blood mononuclear cells (PBMCs), isolated from five milk-allergic patients undergoing rush milk desensitization, were thawed and labeled with carboxyfluorescein succinimidyl ester (CFSE), and cultured in the presence of tetanus toxoid (TT) or milk proteins (MPs) for 7 days. Cells were then collected, stained with anti-CD4 monoclonal antibody, and analyzed by flow cytometry. The number in each panel represents the fraction of total CD4+ cells that are within the $\mathrm{CFSE}^{\text {low }} \mathrm{CD}^{+}$gate (antigen-specific proliferating cells) on day 0 . Mean CD4 ${ }^{+}$milk-specific proliferating cells $=7.75 \%$; mean $\mathrm{CD} 4^{+}$tetanus-specific cells $=24.6 \%$. Mean $\mathrm{CD}^{+}{ }^{+}$proliferating cells without antigen $=0.62 \%$. (b) Each line represents data for all five patients combined (solid line, MP; dashed line, TT). Data represent mean \% antigen-specific cells (CFSElow $\mathrm{CD}^{+}{ }^{+}$cells) of total CD4 ${ }^{+}$cells, normalized to day 0 for each patient \pm s.e.m., over the course of the study. ${ }^{\star \star} P<0.01,{ }^{* \star *} P<0.001$ vs. baseline and week 8 , determined using paired $t$-test. ${ }^{\circ} P<0.05$ vs. TT response, determined using twoway analysis of variance for matched values with Bonferroni's post hoc test. (c) Each line represents data for an individual patient, of \% milk-specific CFSElow $\mathrm{CD}^{+}{ }^{+}$cells of total CD4 ${ }^{+}$cells, normalized to day 0 for each patient, over the course of the study. 
antigen $=0.62 \%)$. However, a striking decrease in milk-specific $\mathrm{CD} 4{ }^{+} \mathrm{T}$-cell proliferation was observed 1 week after initiation of desensitization in all five patients examined, which persisted as the daily dose of milk increased (during weeks 8-16; Figure 1b and c). This effect was specific for the milk-induced response, and was not observed with the TT response. Importantly, the response to milk returned over the ensuing 3-4 months, while the subjects remained on daily oral milk. Although omalizumab treatment was stopped at week 16 and coincided with the increase in milk-specific proliferation, there was no appreciable change in the TT response.

\section{Absence of functional milk-specific $\mathrm{T}_{\text {Reg }}$ cells during the desensitization}

We examined possible mechanisms for the initial transient reduction in the milk-specific proliferative response. Surprisingly, we found no evidence for an increase in the

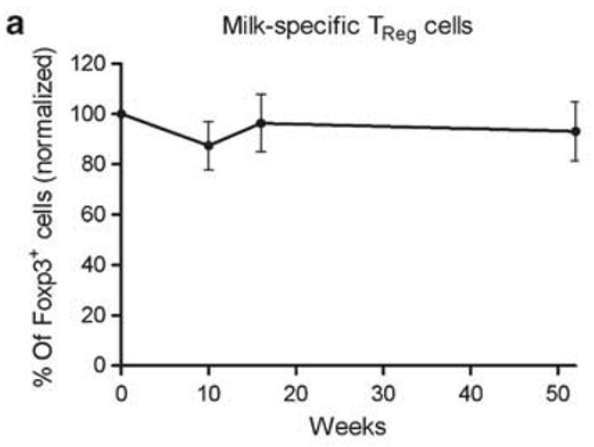

C
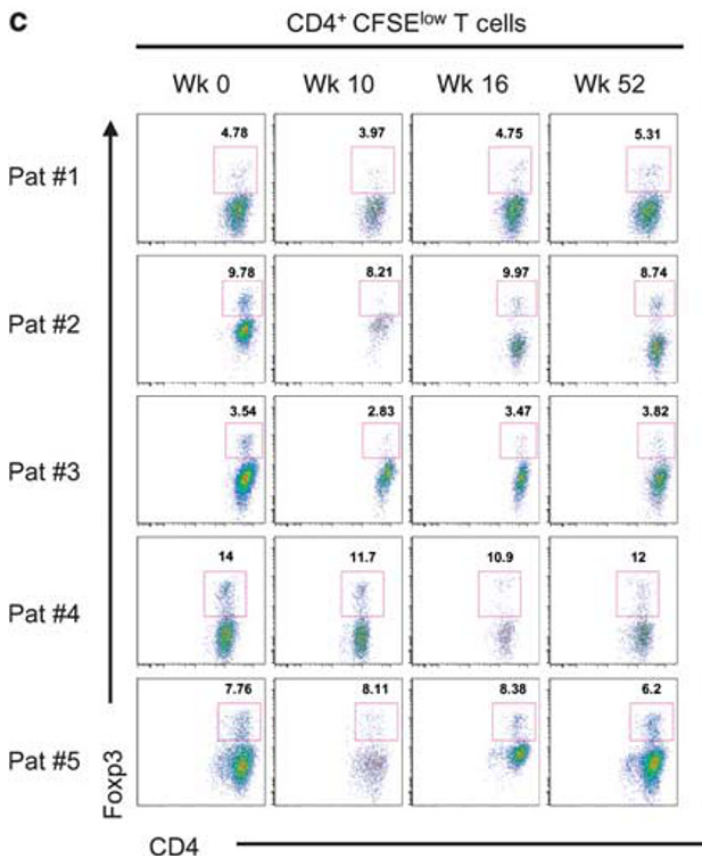

number of milk-specific $\mathrm{T}_{\text {Reg }}$ cells $\left(\mathrm{CFSE}^{\text {low }} \mathrm{CD} 4^{+}\right.$Foxp $^{+}$) in the cultures stimulated with MPs (Figure 2a). As $\mathrm{T}_{\text {Reg }}$ cells may not proliferate, we also examined CFSE ${ }^{\text {high }}$ (nonproliferating cells) and found no increase in the number of $\mathrm{CD}^{+}{ }^{+}$Foxp $3^{+} \mathrm{T}_{\text {Reg }}$ cells (Figure $\mathbf{2 b}$ and $\mathbf{c}$ ). Furthermore, we showed that interleukin (IL)-10 secreting suppressive/ $\mathrm{T}_{\text {Reg }}$ cells were not responsible for the reduced proliferation, as no increase in milk-induced $\mathrm{CD} 4{ }^{+} \mathrm{T}$-cell proliferation was observed in the presence of anti-IL-10 mAb (Figure 3a). Moreover, addition of anti-10 and anti-transforming growth factor- $\beta\left(5 \mu \mathrm{g} \mathrm{ml}^{-1}\right) \mathrm{mAb}$ together did not increase the milkinduced proliferative response at any time point, indicating that IL-10/transforming growth factor- $\beta$ producing $\mathrm{T}_{\text {Reg }}$ cells were not responsible for the reduction in the response to milk (data for week 12, Figure 3b). Finally, we performed mixing experiments, in which purified CD4 ${ }^{+} \mathrm{T}$ cells or CD $4^{+} \mathrm{CD} 25^{+} \mathrm{T}\left(\mathrm{T}_{\mathrm{Reg}}\right)$ cells from PBMCs collected at weeks 12 and 14, when the proliferative
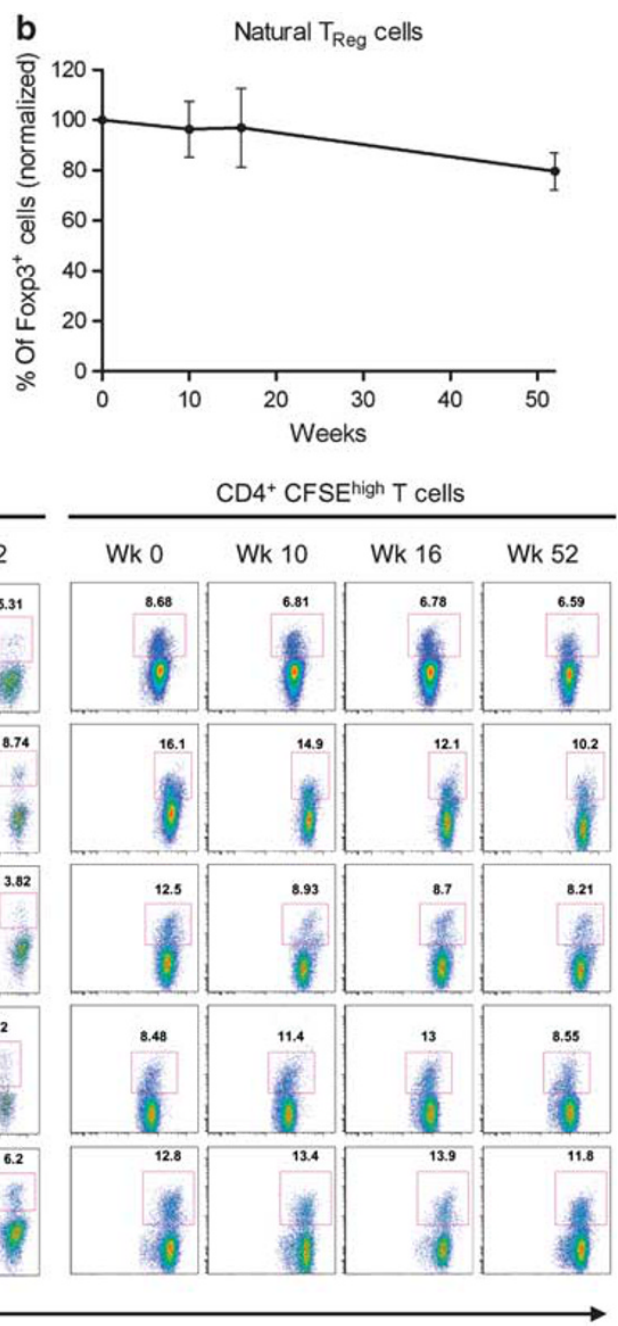

Figure 2 Milk-specific Foxp3 ${ }^{+}$T cells are not detected during the milk desensitization. (a-c) Carboxyfluorescein succinimidyl ester (CFSE)-labeled peripheral blood mononuclear cells (PBMCs) isolated from five milk-allergic patients undergoing milk desensitization was cultured in the presence of milk proteins for 7 days. Cells were then collected, fixed and permeabilized, stained with anti-CD4 and anti-Foxp3, and analyzed by flow cytometry. (a, b) Figures represent combined percentages of $\mathrm{CD}^{+}{ }^{+} \mathrm{Foxp}^{+}$cells of total cells normalized to day 0 . Data represent mean \pm s.e.m. (a) Normalized CD4 ${ }^{+}$CFSElow cells (proliferating cells, representing milk-specific $\mathrm{T}_{\text {Reg }}$ cells). (b) Normalized CD4 ${ }^{+}$CFSE ${ }^{\text {high }}$ cells (nonproliferating cells, representing natural $\mathrm{T}_{\text {Reg }}$ cells). (c) Individual dot plots of flow cytometry analysis are shown. CD4 ${ }^{+}$CFSElow $\mathrm{T}_{\text {cells }}$ (left panels) represent milk-specific $\mathrm{T}_{\text {Reg }}$ cells, which did not increase over time. CD4 ${ }^{+}$CFSE high $T$ cells (right panels) represent natural $T_{\text {Reg }}$ cells, which did not change over time. $T_{\text {Reg }}$, regulatory $T^{2}$ cells. 


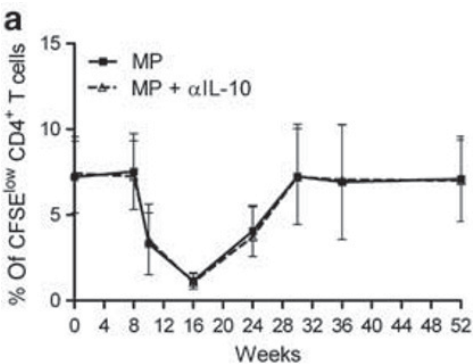

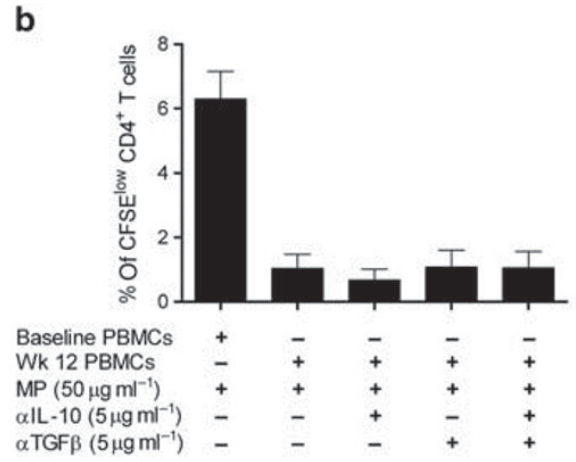

Figure 3 Functional regulatory T cells are not detected during the milk desensitization. (a, b) Carboxyfluorescein succinimidyl ester (CFSE)-labeled peripheral blood mononuclear cells (PBMCs) isolated from five patients undergoing milk desensitization was cultured in the presence of milk protein (MP) for 7 days. Cells were then collected, stained with anti-CD4 monoclonal antibody (mAb), and analyzed by flow cytometry. (a) Frozen samples from multiple time points were thawed and cultured with or without anti-interleukin (IL)-10 mAb and MPs. Percentages of the milk-specific cell populations (CFSE ${ }^{\text {low }}$ ) within the $\mathrm{CD}^{+}$gate are shown. Results with and without anti-IL-10 mAb overlap, indicating an absence of IL-10-mediated suppression. (b) PBMCs from week 12 were cultured with or without anti-IL-10, anti-transforming growth factor (TGF)- $\beta$ mAb or both and compared with baseline PBMCs. Figures represent percentages of the milk-specific cell populations (CFSElow) within the CD4 ${ }^{+}$gate. No increase in proliferation was observed with the mAbs, indicating an absence of IL-10 or TGF- $\beta$-mediated suppression. (c) CD4 ${ }^{+} \mathrm{T}$ cells and regulatory T cells were purified from week 12 and week 14 PBMCs, respectively. $1 \times 10^{4}(+)$ or $5 \times 10^{4}(++)$ CD4 ${ }^{+}$CD25+ cells, or $1.5 \times 10^{4}(+)$ or $7.5 \times 10^{4}(++)$ CD4 $4^{+}$cells were then cocultured with $2 \times 10^{5}$ baseline PBMCs in the presence of MPs. The proliferation was measured as $\left[{ }^{3} \mathrm{H}\right]$-thymidine incorporation during the last $16 \mathrm{~h}$ of a 6 -day culture. CPM, counts per minute.

response was low, were cultured with PBMCs from week 0. In these experiments, milk-induced proliferation was assessed by $\left[{ }^{3} \mathrm{H}\right]$-thymidine incorporation during the last $16 \mathrm{~h}$ of a 6-day culture. Neither $\mathrm{CD} 4^{+} \mathrm{T}$ cells nor $\mathrm{CD} 4{ }^{+} \mathrm{CD} 25^{+}$cells were able to reduce the week 0 PBMC response to milk (Figure $3 \mathrm{c}$ ). Together, these results suggest that $\mathrm{T}_{\text {reg }}$ cells were not involved in the reduction of the milk-specific $\mathrm{CD} 4^{+} \mathrm{T}$-cell proliferation observed during desensitization at weeks 10-14.

\section{Evidence for milk-specific T-cell anergy}

We next examined whether anergy, defined by lack of responsiveness to antigen that can be restored with IL-2 and associated with the absence of suppressive activity, ${ }^{20}$ could explain the reduced milk-specific T-cell proliferative response. First, treatment of milk-activated $\mathrm{CD} 4^{+} \mathrm{T}$ cells isolated at week 12 with IL-2 partially restored the proliferation of milk-specific CD4 ${ }^{+}$ $\mathrm{T}$ cells, although this increase only trended toward statistical significance $(P=0.07$; Figure 4a). Furthermore, we found that during the initial desensitization period (weeks 10 and 16), the limited number of $\mathrm{CD} 4^{+} \mathrm{T}$ cells responding to milk expressed lower levels of CD25 (an activation antigen) compared with that at week 0 (Figure $4 \mathbf{b}$ ), suggesting that the milk-specific cells at these time points could not be fully activated. In contrast, milk-specific T cells from patient \#3, who was only partially desensitized (reacted at the $1,000 \mathrm{mg}$ dose during the doubleblind placebo-controlled food challenge at week 24), and who had less of a reduction in milk-induced proliferation at week 10 (Figure 1c), had no reduction in CD25 expression at weeks 10 and 16 compared with week 0 (Figure $4 \mathbf{c}$ and $\mathbf{d}$ ). Moreover, in the one patient in whom PD-1, an antigen expressed by anergic or exhausted $\mathrm{T}$ cells, ${ }^{21,22}$ was examined (patient \#5, who was successfully desensitized), we found that milk-specific $\mathrm{CD} 4^{+}$ T cells expressed a significant increase in PD-1 at weeks 10 and 16 (as well as reduced levels of CD25) compared with week 0
(Supplementary Figure S1 online). These results together suggest that anergy could, at least in part, explain the reduction of milk-specific $\mathrm{CD} 4^{+} \mathrm{T}$-cell proliferation observed after the rush desensitization phase.

\section{Evidence for immune deviation during milk desensitization} Although the cytokine profile of the milk-specific CFSE ${ }^{\text {low }}$ $\mathrm{CD}^{+} \mathrm{T}$ cells did not change appreciably during the first 30 weeks, the ratio of interferon (IFN)- $\gamma /$ IL-4 production of the milk-specific $\mathrm{T}$ cells increased substantially between weeks 36 and 52 (Figure 5a). This increase in the IFN- $\gamma /$ IL-4 ratio was observed in patients who passed the double-blind placebo-controlled food challenge and were fully desensitized (Figure 5b and c), but was delayed for patient \#3 who was only partially desensitized (Figure $5 \mathbf{b}$ ). IL-13 production in the milk-specific $\mathrm{CD} 4^{+} \mathrm{T}$ cells was examined in one patient (\#5), and found to follow IL-4 production, in that the IFN- $\gamma /$ IL-13 ratio increased after week 30 (Figure 5d). The increase in the IFN- $\gamma / \mathrm{IL}-4$ ratio in the milk-specific $\mathrm{CD} 4^{+} \mathrm{T}$ cells suggests that immune deviation developed late during the desensitization, consistent with the significant reduction in milk-specific IgE at weeks 36 and 52 observed in all 10 patients examined (Figure 5e), and by a 15 -fold increase in milk-specific IgG4 seen after week 24 in all 10 patients (Figure 5f).

\section{Milk-specific basophil activation is reduced by milk desensitization}

On enrollment, all 10 patients who completed the study had significant immediate skin reactivity to milk (week 0 ). However, by week 52 of the study, immediate skin prick test responses to cow's milk were reduced compared with week 0 in 9 of the 10 patients $(P<0.01$; Figure 6a). In contrast, there was no statistically significant change in immediate skin testing to other allergens (cashew or egg) at week 52 compared with week 0 , in 

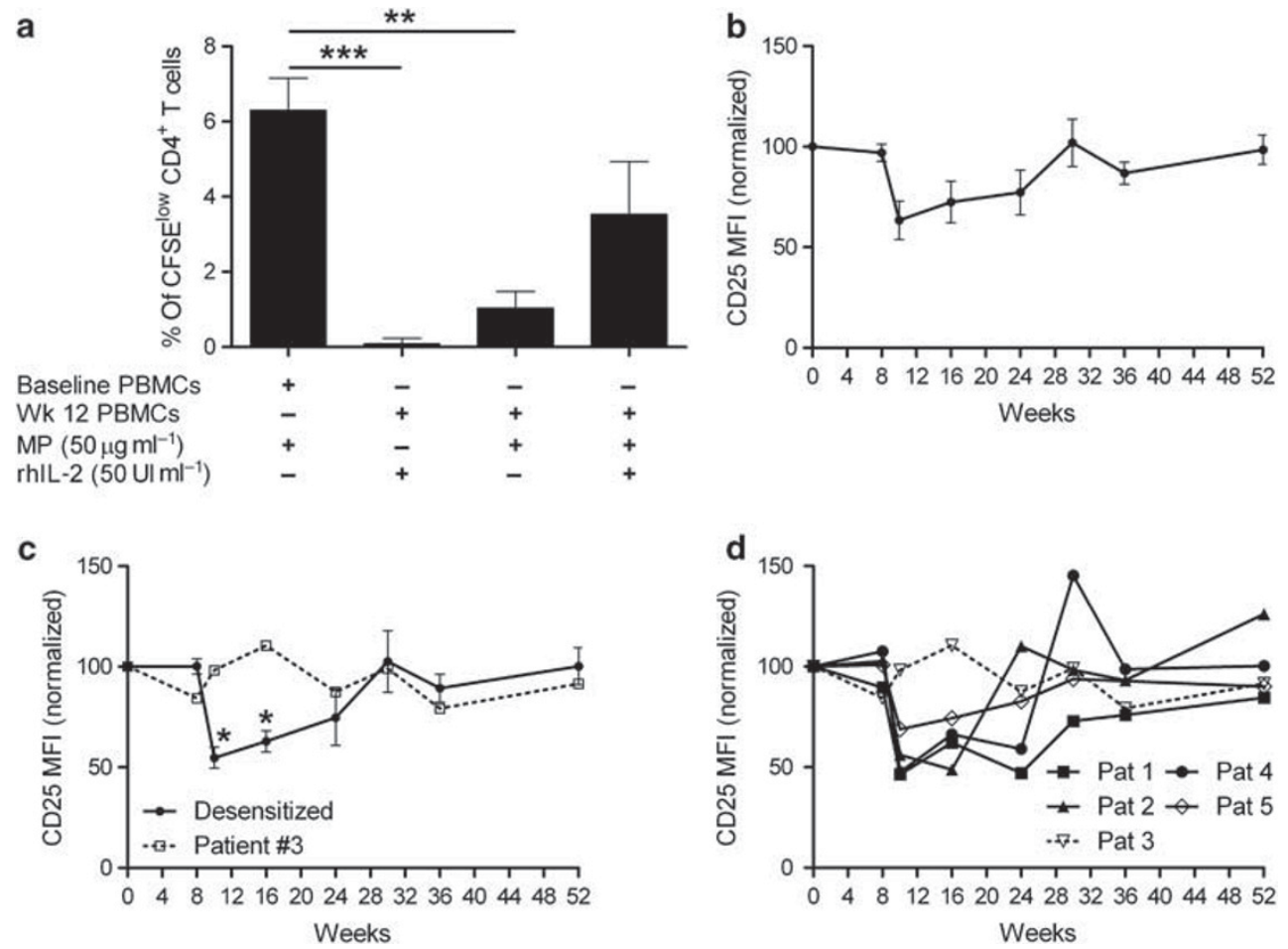

Figure 4 Evidence of milk-specific CD4 ${ }^{+}$T-cell anergy. (a) Peripheral blood mononuclear cells (PBMCs) were isolated from week 12 samples of five milk-allergic patients undergoing milk desensitization protocol, labeled with carboxyfluorescein succinimidyl ester (CFSE), cultured in the presence of milk proteins (MPs) for 7 days and treated with or without interleukin-2. Cells were then collected and stained with anti-CD4 monoclonal antibody. Proliferation was analyzed by flow cytometry and compared with PBMC proliferation from baseline samples. Figure shows percentages of the milkspecific cells (CFSElow) within the CD4 ${ }^{+}$gate as mean \pm s.e.m. for five patients; ${ }^{* *} P<0.01,{ }^{* * *} P<0.001$. Significance was determined using paired $t$-test. (b-d) Phenotype of the milk-specific CD4 ${ }^{+} \mathrm{T}$ cells during desensitization. CFSE-labeled PBMCs isolated from all five of the milk-allergic patients undergoing milk desensitization were cultured in the presence of milk proteins for 7 days, then analyzed by flow cytometry. (b) Data represent CD25 expression (mean CD25 MFI (mean fluorescence intensity)) by milk-specific (CD4+ CFSElow) cells \pm s.e.m. for the five patients evaluated, normalized to results on day 0 . (c) Solid line represents CD25 expression (mean MFI) for milk-specific cells from the four patients who were desensitized and who passed the double-blind placebo-controlled food challenge, normalized to results on day 0 . Dashed line represents CD25 expression (MFI) by milkspecific cells from patient \#3, who was only partially desensitized, normalized to results on day $0 .{ }^{*} P<0.05$ vs. baseline and week 8 , using paired $t$-test. (d) Each line represents CD25 expression (MFI) on milk-specific cells from each patient normalized to results on day 0 . Patient \#3 was only partially desensitized.

the four patients who were skin tested to these other allergens (Figure 6b).

Similarly, in in vitro studies, we found that cow's milk antigen, but not vehicle, activated peripheral blood basophils taken on enrollment (week 0 ), as demonstrated by an increase in basophil expression of CD203c and CD63 (basophil activation markers); in histamine release $(P<0.001$; Figure $6 \mathbf{c})$; and in phospho-Syk expression Supplementary Figure S2 online). However, treatment of the patients with omalizumab, beginning on week 0 and continuing through week 16 , greatly reduced milk-induced basophil activation (Figure 6c, Supplementary Figure S2 online, weeks 8-16). Importantly, the reduction in milk-induced basophil activation persisted after omalizumab was discontinued (weeks 24-52), presumably reflecting a milk-desensitized state, and consistent with the reduction of milk-specific skin test reactivity at week 52 and reduced milk-specific IgE at weeks 36 and 52. The reduction in milk-induced basophil activation at weeks 24-52 was antigen-specific, as egg and cashew antigens activated the basophils obtained at weeks 24-52, after discontinuation of omalizumab treatment, as demonstrated by increased antigeninduced expression of CD203c and CD63; increase in histamine release (Figure 6d); and increase in phospho-Syk expression (Supplementary Figure S2 online). The basophil response to egg and cashew at weeks $24-52$ were not quite as robust as at week 0 , but were clearly much greater than the very limited basophil responses observed at weeks $8-16$, when the patients were being treated with omalizumab. These results together indicated that the mast cell compartment (i.e., mast cells in the skin and basophils in the peripheral blood) was greatly inhibited in an allergen-nonspecific manner during omalizumab treatment, and in an antigen-specific manner after completion of the oral milk desensitization protocol.

\section{DISCUSSION}

Food allergy is a major public health problem that has increased dramatically in prevalence in industrialized countries over the past 10-15 years. ${ }^{23,24}$ Unfortunately for patients with food allergy, there is no effective treatment except to avoid the offending foods, and to have ready access to self-injectable epinephrine. ${ }^{25}$ Recently, however, several reports indicate that oral desensitization may be effective in patients with allergy to several different foods, including milk, egg, peanut, and 
a

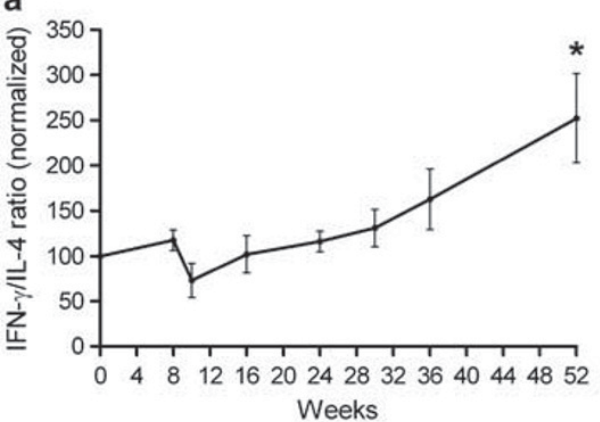

C

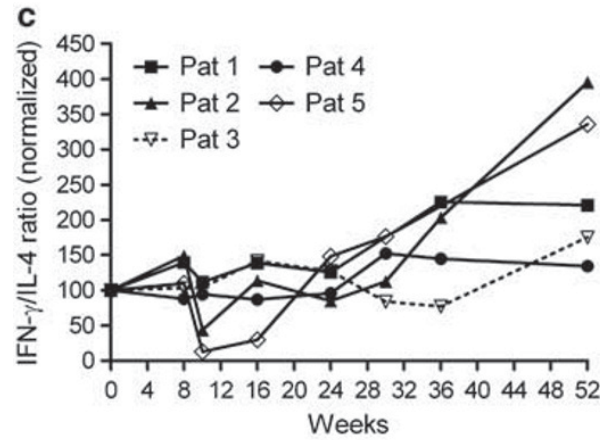

e

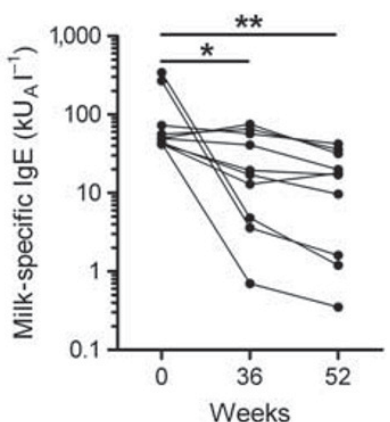

b

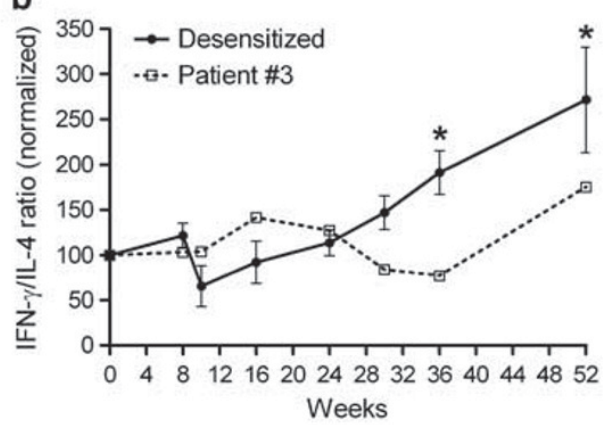

d

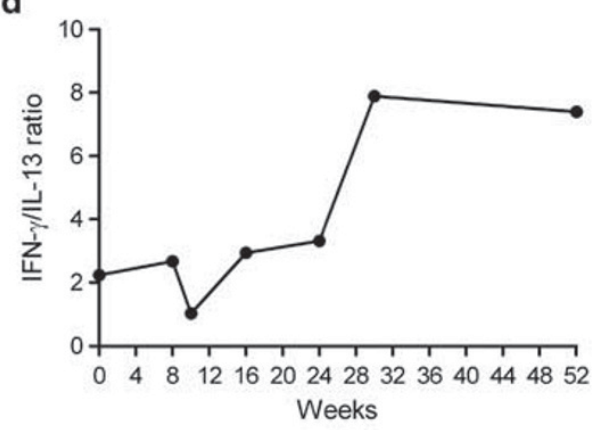

f

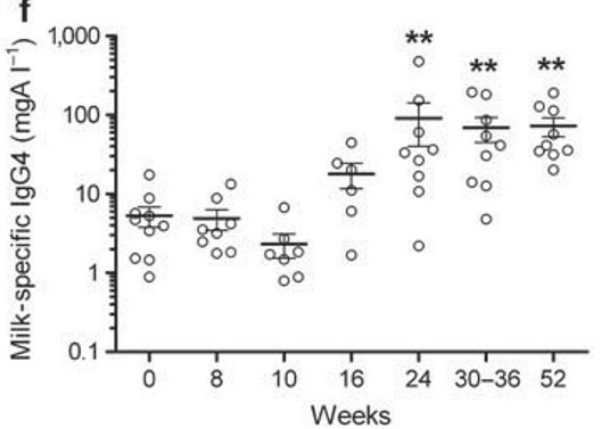

Figure 5 Evidence for immune deviation during milk desensitization. (a-c) Peripheral blood mononuclear cells (PBMCs) isolated from five milkallergic patients undergoing milk desensitization, labeled with carboxyfluorescein succinimidyl ester (CFSE), and cultured in the presence of antigens for 7 days, were restimulated with phorbol myristate acetate and ionomycin in the presence of monensin for $5 \mathrm{~h}$. Cytokine production was then assessed using intracellular interleukin (IL)-4, interferon (IFN)- $\gamma$, and IL-13 staining. (a) Data for all five patients. IFN- $\gamma /$ IL-4 production ratio for the antigen-specific (CFSE ${ }^{\text {low }}$ ) CD4 ${ }^{+} T$ cells, normalized to day 0 is shown (mean \pm s.e.m.). (b) Solid line represents data from panel a, for desensitized patients (patients \#1, 2, 4, and 5), and dotted line represents data from panel a, for the partially desensitized patient (patient \#3). ${ }^{\star} P<0.05$ vs. baseline and week 8, using paired $t$-test. (c) Each line represents data for an individual patient, representing IFN- $\gamma /$ IL-4 production ratio by the antigen-specific $\mathrm{CD}^{+} \mathrm{T}$ cells, normalized to day 0 . (d) IL-13 production was also assessed in CD4 ${ }^{+} \mathrm{T}$ cells from patient \#5. Data represent IFN- $\gamma / \mathrm{IL}-13$ production by milk-specific CD4+ T cells. (e, f) Serum milk-specific immunoglobulin (Ig)E (e) and lgG4 (f) levels were determined for the 10 patients who completed the study. Points represent data from different individuals, and bars show mean values \pm s.e.m. ${ }^{*} P<0.05,{ }^{* \star} P<0.01$ vs. baseline, determined using nonparametric Wilcoxon matched-pairs test.

hazelnut. ${ }^{14-18,26-30}$ The protocols for desensitization are diverse, and even with a given protocol, the pace at which the dose of allergen increases varies considerably between patients, due to unpredictable allergic reactions, which confounds the analysis of mechanisms that mediate oral desensitization. As a result, the mechanisms of oral desensitization in patients with food allergy are poorly understood.

In this study, we examined the mechanisms of oral desensitization in a small group of children, who tolerated a novel, relatively rapid and uniform, presumably high-dose oral desensitization protocol, enabled with omalizumab, which was used in this setting for the first time. ${ }^{19}$ After stopping omalizumab, nine of the children added normal amounts of milk ( $>8-12 \mathrm{~g}$ per day, equivalent to $>240-360 \mathrm{ml}$ per day) to their diets 15-19 weeks after starting the oral desensitization, and the 10th child was able to consume $1-2 \mathrm{~g}$ of milk daily by week 52 . Because enrollment in this study was restricted to children with high levels of serum milk-specific $\operatorname{IgE}$ (median milk-specific $\operatorname{IgE} 50 \mathrm{kU}_{\mathrm{A}} 1^{-1}$, mean $98 \mathrm{kU}_{\mathrm{A}} 1^{-1}$ ), which are associated with milk allergy that is less likely to resolve, ${ }^{31}$ we believe that the immunological changes observed in these patients are highly significant.

Using CFSE labeling of PBMCs in our analysis, we focused on milk-specific $\mathrm{CD} 4^{+} \mathrm{T}$ cells and found that prior to desensitization, the milk-specific $\mathrm{CD} 4^{+} \mathrm{T}$ cells were $\mathrm{T}$ helper 2-skewed, 
a

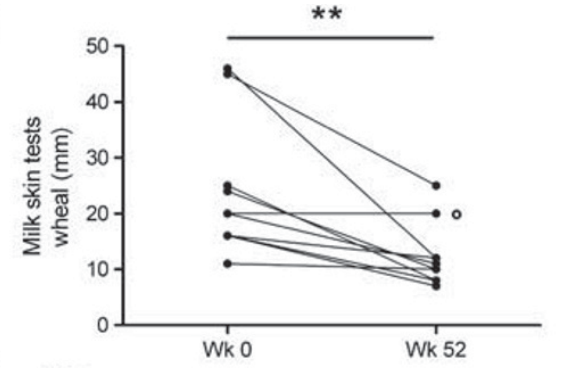

C


b
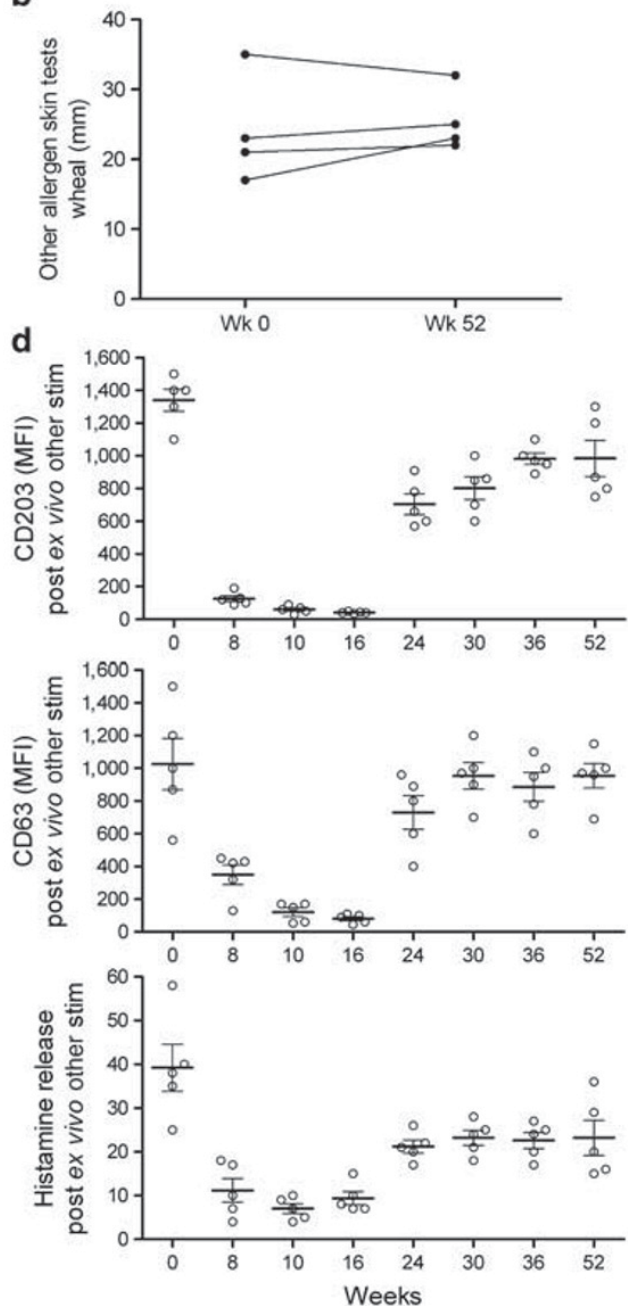

Figure 6 Milk skin test reactivity and in vitro basophil activation are reduced by oral milk desensitization. (a) Skin prick test wheal with cow's milk allergen extract $(n=10)$ was reduced at week 52 compared with week $0 .{ }^{* *} P<0.01$ determined using paired $t$-test. ${ }^{\circ}$ Patient \#3, who was slow to become desensitized. (b) Skin prick test wheal with cashew or ovalbumin did not change, comparing week 0 and week 52 time points in four patients known to have those allergies. (c) Basophils in whole blood, taken on day 0 , but not subsequently, when stimulated ex vivo for 20 min with cow's milk $(C M)$, were activated, as assessed by expression of CD203c, CD63, and histamine release $(n=5)$. Treatment with vehicle/glycerine showed no shift in CD203c or CD63 expression (data not shown); MFI, median fluorescence intensity. (d) Basophil activation with cashew or ovalbumin was blocked by in vivo treatment with omalizumab, as assessed on weeks 8, 9, 10, and 16. Prior to and after omalizumab treatment, basophil activation with cashew or ovalbumin was robust, as assessed by expression of CD203c, CD63, and histamine release.

as expected, ${ }^{9,11,12}$ but that rapid high-dose allergen administration greatly, but temporarily, decreased milk-induced, but not tetanus-induced, $\mathrm{CD} 4{ }^{+}$T-cell proliferation. Surprisingly, the acute reduction in milk-specific T-cell proliferation in the patients examined was not associated with the development of allergen-specific Foxp3 ${ }^{+} \mathrm{T}_{\text {Reg }}$ cells, nor was there evidence of suppression, as shown by coculture experiments. Moreover, the reduction in milk-specific $\mathrm{CD} 4{ }^{+} \mathrm{T}$-cell proliferation that occurred during the rapid desensitization period could be partially reversed with the addition of IL-2 to the cultures. This suggested that high-dose milk administration resulted initially in the development of milk-specific $\mathrm{CD} 4{ }^{+} \mathrm{T}$-cell anergy and possibly deletion, ${ }^{18}$ although additional studies must be performed to fully understand the mechanisms of high-dose oral desensitization, particularly because of the limited number of patients analyzed.
Rapid reductions in allergen-specific $\mathrm{CD} 4^{+} \mathrm{T}$-cell responses have been previously observed in beekeepers exposed to multiple bee stings due to the development of venom-specific $\mathrm{T}_{\mathrm{Reg}}$ cells. ${ }^{7}$ In these subjects, venom-specific IL-10-producing $\mathrm{T}_{\mathrm{Reg}}$ cells developed with repeated bee stings (average cumulative antigen dose over 7 months was $<1-4 \mathrm{mg}$ ). Similarly, subcutaneous immunotherapy with grass pollen and bee venom, in which the allergen doses are low, ranging from 4 to $100 \mu$ g per dose, as well as with cat allergen peptides, induced allergen-specific tolerance associated with the development of allergen-specific $\mathrm{T}_{\text {Reg }}$ cells producing IL-10.6,32-35 There results are consistent with the idea that administration of low doses of antigen during immunotherapy induces allergen-specific $\mathrm{T}_{\mathrm{Reg}}$ cells. ${ }^{8}$

In contrast, in our study of oral desensitization, we used much higher doses of antigen (gram amounts daily), and surprisingly, desensitization was not associated with IL-10-producing 
milk-specific $\mathrm{T}_{\text {Reg }}$ cells. Furthermore, we failed to observe an increase in the number of Foxp $3^{+}$, natural $\mathrm{T}_{\text {Reg }}$ cells, which are thought to primarily prevent the development of autoimmunity. ${ }^{36}$ Several studies have shown that the frequency of natural Foxp $3^{+} \mathrm{CD} 4{ }^{+} \mathrm{CD} 25^{+} \mathrm{T}_{\mathrm{Reg}}$ cells increased after peanut oral immunotherapy, ${ }^{37,38}$ although this was not observed in other studies. ${ }^{39-41}$ It is possible that in our patients, milkspecific $\mathrm{T}_{\text {Reg }}$ cells and/or natural Foxp $3{ }^{+} \mathrm{CD} 4{ }^{+} \mathrm{CD} 25^{+} \mathrm{T}_{\mathrm{Reg}}$ cells were present only in the gastrointestinal tract, or could develop later, e.g., after 12-18 months of daily oral milk maintenance. Alternatively, it is possible that milk-specific $\mathrm{T}_{\mathrm{Reg}}$ cells develop only with low-antigen exposure, e.g., induced by exposure to small amounts of milk, and prior to ingestion of full dietary quantities of milk. ${ }^{13}$

In our patients, after 4-6 months of daily high doses of oral milk, we found that a vigorous milk-specific $\mathrm{CD} 4{ }^{+} \mathrm{T}$-cell response returned, but still without evidence of milk-specific Foxp $3^{+} \mathrm{T}_{\mathrm{Reg}}$ cells. This robust milk-specific T-cell response, associated with increased production of IFN- $\gamma$, a 15 -fold increase in milk-specific IgG4, as well as reduced milk-specific IgE, suggested that high-dose oral desensitization evolved into a form of immune deviation. A similar Th1-like allergenspecific response was reported in peanut-allergic individuals who had naturally outgrown their sensitivity, ${ }^{12}$ and in milkspecific Peyer's patch T cells from nonallergic individuals. ${ }^{42}$ In those studies, similar to our desensitized subjects, the presence of food-specific Foxp3 ${ }^{+} \mathrm{T}_{\mathrm{Reg}}$ cells was also not observed, suggesting that high-dose allergen-specific tolerance may not always be associated with allergen-specific Foxp $3^{+} \mathrm{T}_{\text {Reg }}$ cells. However, it is possible that the milk-specific $\mathrm{CD} 4^{+} \mathrm{T}$ cells producing IFN- $\gamma$ that we observed may exert inhibitory activity on IgE-mediated milk-induced symptoms through unclear mechanisms, ${ }^{43,44}$ particularly as milk-specific IgE was still present after the desensitization in most of our patients. Alternatively, it is possible that milk-specific IgG4 may have a very dominant role in inhibiting IgE-mediated symptoms and inflammation. ${ }^{3}$

At present, all of our subjects have fully completed the 52week study, and remain on daily oral milk to maintain their desensitized state. The patients continue to be followed, and over time it is possible that a more permanent tolerant state may develop, such that the capacity to tolerate milk may persist even after oral milk dosing is discontinued ${ }^{45}$ perhaps indicating a clinical 'cure' of the allergy. However, on the basis of the experience with subcutaneous immunotherapy with inhalant allergens and bee venom, in which long-lived symptom control and allergen 'tolerance' is achieved only after completing 3-5 years of 'maintenance' therapy, ${ }^{46,47}$ complete milk-specific immunological 'tolerance' may require several years of frequent milk exposure. On the other hand, because the antigen doses with oral desensitization are much greater than that of subcutaneous immunotherapy, it is possible that immunological tolerance might develop sooner with oral immunotherapy, as has been suggested. ${ }^{18,48}$

In summary, we examined milk-specific immune responses in a small number of patients who completed a novel, rapid, and uniform high-dose oral milk immunotherapy protocol enabled with omalizumab. Within a week of the initial rapid oral desensitization, we observed an acute and significant reduction of milk-specific T-cell responses, without evidence of Foxp3 ${ }^{+}$ $\mathrm{T}_{\text {Reg }}$ cell development, suggesting the induction of anergy in, or deletion of, effector $\mathrm{T}$ cells. The reduced or anergic response was later replaced by a vigorous $\mathrm{CD} 4{ }^{+} \mathrm{T}$-cell response, characterized by a shift from IL- 4 to greater IFN- $\gamma$ production, and associated with reduced milk-specific IgE production, reduced milkspecific basophil degranulation, and increased milk-specific IgG4 production. Although our study included a very small number of patients, and requires replication and confirmation in a much larger patient population, the immunological changes observed in the desensitized patients were surprisingly uniform and statistically significant. These results suggest that rapid high-dose oral desensitization induces allergen-specific immune deviation not associated with Foxp $3^{+}$allergen-specific $\mathrm{T}_{\text {Reg }}$ cells, reminiscent of allergen-specific immunity associated with the natural resolution of food allergy. ${ }^{12}$ In addition, these results provide an improved understanding of high-dose oral desensitization in humans, and could lead to better therapies and diagnostic methods for patients with food allergies.

\section{METHODS}

Study population. Eleven patients with a history of significant IgEmediated milk allergy (defined as having a significant immediate reaction on accidental ingestion of milk, including generalized urticaria, vomiting, and/or anaphylaxis) were enrolled in the study at two sites, the Children's Hospital Boston and at Stanford University School of Medicine. The subjects included seven boys and four girls. Ten of 11 subjects had a past or current history of eczema, asthma, or both, 10 had a history of at least 1 other food allergy, and 6 had 2 or more additional food allergies. The mean age of the patients was 10.2 years (median 8; range 7-17 years), the median milk-specific $\operatorname{IgE}$ was $50 \mathrm{kU}_{\mathrm{A}} \mathrm{l}^{-1}$ (mean 98, range 42-342 $\mathrm{kU}_{\mathrm{A}} \mathrm{l}^{-1}$, normal $<0.35$; Phadia ImmunoCAP System; Phadia, Kalamazoo, MI), and the median skin prick test wheal responses to milk extract was $22 \mathrm{~mm}$ (mean 20, range $11-46 \mathrm{~mm}$ ). ${ }^{19}$ The institutional review boards of both institutions approved the clinical protocols, and all participants and/or their parents provided written informed consent. The trial was registered at www.clinicaltrials.gov (NCT00968110).

Clinical protocol. Patients were pretreated with omalizumab for 9 weeks, allowing IgE to detach from FcER1 on the surface of mast cells and bind to omalizumab, before starting the oral desensitization to cow's milk. ${ }^{19}$ At week 9, the oral desensitization began with $0.1 \mathrm{mg}$ of cow's MP (dried nonfat powdered milk, Carnation Instant Milk, Nestle, Wilkes-Barre, PA) mixed in water. There were 12 doses on the first day of desensitization $(0.1,0.5,1.5,3,7,15,30,60,125,250,500$, and $1,000 \mathrm{mg})$ given every $30 \mathrm{~min}$ (cumulative dose 1,992 mg). One subject voluntarily discontinued the study after the 5 th oral dose due to vomiting, later diagnosed as abdominal migraines. The day after the rush desensitization, patients returned to start the slower dose escalation, build-up phase, and received the highest dose of milk achieved on the previous day, up to $1,000 \mathrm{mg}$. Subjects received the same daily dose at home for the next 6 days. The subjects returned weekly for an increase in the oral dose (increase of $12.5 \%$ ) until a daily oral dose of $2,000 \mathrm{mg}$ was attained (over a period of 7-11 weeks). At week 16, omalizumab treatment was discontinued, while daily oral milk continued. Treatment with omalizumab was extended by $2-4$ weeks in 2 of 10 remaining subjects, to allow the milk dose to increase to $2,000 \mathrm{mg}$. At week 24 ( 8 weeks after discontinuing the omalizumab), a double-blind placebo-controlled food challenge to milk was conducted. The challenge consisted of 5 doses administered orally every $15 \mathrm{~min}: 500$, 
$750,1,000,2,000$, and 3,000 $\mathrm{mg}$ (cumulative dose 7,250 mg). Nine of the 10 remaining subjects passed the double-blind placebo-controlled food challenge, and an open challenge of 4,000-8,000 mg (120-240 ml) of milk was given $2-16 \mathrm{~h}$ later.

Patient samples. Blood was taken at multiple time points before, during, and after the desensitization protocol (weeks $0,8,9,10,12$, $14,16,24,30,36$, and 52). PBMCs were isolated from the blood of five patients (at the Children's Hospital Boston site) by density-gradient separation using Histopaque-1077 (Sigma-Aldrich, St Louis, MO). The PBMCs were frozen in aliquots and stored in liquid nitrogen for later examination. In all experiments, PBMC aliquots from multiple time points for each patient were thawed and studied together, so that changes in the phenotype/function of the cells over time could be assessed accurately. Fresh blood samples from five patients (at the Stanford site) were used to study basophil function.

CFSE labeling and cell culture. PBMCs were labeled with CFSE by incubating PBMCs $\left(2 \times 10^{7}\right.$ cells $\left.\mathrm{ml}^{-1}\right)$ in RPMI with $2.5 \mu \mathrm{M}$ CFSE for $8 \mathrm{~min}$ at $37^{\circ} \mathrm{C}$ with gentle shaking, then washing excess dye away. CFSE-labeled PBMCs were then cultured in the presence of MPs ( $\alpha$ casein, $\beta$-casein, $\alpha$-lactalbumin, $\beta$-lactoglobulin (Sigma-Aldrich), each at a concentration of $\left.12.5 \mu \mathrm{g} \mathrm{ml}^{-1}\right)$, TT $\left(0.5 \mu \mathrm{g} \mathrm{ml}^{-1}\right)$, or left unstimulated in RPMI-1640 containing gentamycin and supplemented with $10 \% \mathrm{AB}+$ serum and glutamine. Cells were distributed in 48 -well flat-bottom plates, at a concentration of $1 \times 10^{6}$ per $800 \mu \mathrm{l}$ medium per well. Some of the cultures were also treated with rhIL2 $\left(50 \mathrm{IU} \mathrm{ml}^{-1}\right)$. After 7 days of culture, PBMCs were collected and stained with phycoerythrin-conjugated anti-CD4 (RPA-T4; BioLegend, San Diego, CA), PerCP/Cy5.5-conjugated anti-CD8 (SK1; BioLegend), allophycocyanin (APC)-conjugated anti-CD25 (BC96; BioLegend), and APC-eFluor 780-conjugated anti-CD3 (UCHT1; eBioscience, San Diego, CA). Some samples were also stained with PerCP/Cy5.5-conjugated anti-CD279 (PD-1) (EH12.2H7; BioLegend), APC-conjugated anti-CD152 (CTLA4) (L3D10; BioLegend), and APC-Cy7-conjugated anti-HLA-DR (L243; BioLegend).

Detection of cytokine production by flow cytometry. After 7 days of culture with MPs, PBMCs were restimulated with phorbol myristate acetate $\left(25 \mathrm{ng} \mathrm{ml}^{-1}\right)$, ionomycin $\left(0.5 \mu \mathrm{g} \mathrm{ml}^{-1}\right)$, and monensin for $5 \mathrm{~h}$, then fixed and permeabilized with BD Cytofix/Cytoperm Fixation/ Permeabilization Kit (BD Biosciences, San Jose, CA), and stained with phycoerythrin-conjugated anti-CD4 (RPA-T4, BioLegend), APC-conjugated anti-IL-4 (8D4-8; BioLegend), and Alexa Fluor 700-conjugated anti-IFN- $\gamma$ (4S.B3; BioLegend). Some cultures were also stained with APC-conjugated anti-IL-10 (JES3-19F1; BD Biosciences) and anti-IL-13 (JES10-5A2; BioLegend). PBMCs cultured in the presence of the same antigens, but not restimulated with phorbol myristate acetate and ionomycin were used as negative controls.

Detection of $\mathbf{T}_{\text {Reg }}$ cells by flow cytometry. After 7 days of culture with MPs, PBMCs were collected, fixed, and permeabilized with Foxp3 Staining Buffer kit (eBioscience), and stained with phycoerythrinconjugated anti-CD4 (RPA-T4, BioLegend) and APC-conjugated anti-FoxP3 (236A/E7; eBioscience).

Study of $\mathbf{T}_{\text {Reg }}$ cell function. CFSE-labeled PBMCs were cocultured in the presence of MPs and treated or not with anti-IL-10 (JES3-9D7, $5 \mu \mathrm{g} \mathrm{ml}^{-1}$; BioLegend) and/or anti-transforming growth factor- $\beta\left(5 \mu \mathrm{g} \mathrm{ml}^{-1}\right) \mathrm{mAbs}$. In another series of experiments, $\mathrm{T}_{\mathrm{Reg}}$ cells and untouched $\mathrm{CD} 4^{+} \mathrm{T}$ cells were purified from PBMCs using the $\mathrm{CD} 4{ }^{+} \mathrm{CD} 25^{+}$Regulatory T Cell Isolation Kit (Miltenyi Biotec, Bergisch, Gladbach, Germany). CD4 ${ }^{+}$ CD $25^{+}$cells ( 1 or $5 \times 10^{4}$ cells) or CD $4^{+}$cells $\left(1.5\right.$ or $7.5 \times 10^{4}$ cells) were then cocultured with $2 \times 10^{5}$ baseline PBMCs in 96-well plates in the presence of MPs. The proliferation was measured as $\left[{ }^{3} \mathrm{H}\right]$-thymidine incorporation during the last $16 \mathrm{~h}$ of a 6 -day culture.
Examination of basophil function. Basophil function was studied as previously described. ${ }^{49}$ Briefly, basophils, identified by gating on at least 500 Live/Dead ${ }^{\text {low }} \mathrm{CD} 3^{-} \mathrm{CD} 16^{-} \mathrm{CD} 20^{-} \mathrm{CD} 56^{-} \mathrm{CD}^{-} 6 \mathrm{~b}^{-} \mathrm{HLA}-$ $\mathrm{DR}^{-} \mathrm{CD} 123^{+}$cells, were assessed by flow cytometry for changes in expression of CD203 and CD63. Antibodies used were CD3 (UCHT1, Alexa 488), CD41a (96.2C1, Alexa 488), CD66b (G10F5, Alexa 488), CD123 (7G3, Alexa 647), and HLA-DR (L243, Alexa 488), from BD Biosciences, and CD203c (NP4D6, purified) from BioLegend. CD203c was custom-conjugated to Pacific Blue (Invitrogen, San Diego, CA) as per the manufacturer's protocol. Histamine released into culture supernatants was detected using standardized enzyme-linked immunosorbent assay methods in quadruplicate.

Prick skin testing. Skin prick tests were conducted via a standardized procedure by a trained, licensed specialist in allergy, using allergens (milk, egg, cashew) from Greer Laboratories (Lenoir, NC).

Determination of serum levels of milk-specific IgE and IgG4. Total milk allergen-specific IgE was quantified in sera collected at time points when patients were not being treated with omalizumab using the ImmunoCAP System (Phadia). IgG4 anti-milk was assessed in sera using the UniCAP 100 (Phadia) by separately measuring IgG4 antibody levels to the three principal milk allergenic components (casein, $\alpha$-lactalbumin, and $\beta$-lactoglobulin). These were summed to provide a measure in $\mu \mathrm{g}$ per $\mathrm{ml}$ of IgG4 anti-milk, as IgG anti-milk could not be directly measured in serum using the milk-extract CAP reagent due to the high prevalence of bovine serum albumin-reactive IgG antibodies in many sera from healthy humans.

Statistics. For most comparisons, we used the paired $t$-test or two-way analysis of variance for matched values. For Ig levels (not distributed in a Gaussian manner), we used nonparametric Wilcoxon tests. Differences were considered significant with $P<0.05$.

SUPPLEMENTARY MATERIAL is linked to the online version of the paper at http://www.nature.com/mi

\section{ACKNOWLEDGMENTS}

This study was supported by NIH UL1 RR 025758 Clinical and Translational Science Center/Harvard Catalyst; NIH UL1 RR 025744 Stanford University; Children's Hospital Boston Translational Research Program; the Bunning Food Allergy Project; the Food Allergy Initiative; Stanford Institute of Immunity, Transplantation, and Infectious Diseases; and the Fund for Food Allergy Research at Stanford. D.B. was supported by a fellowship from the Belgian American Educational Foundation and later by a fellowship from the Thrasher Research Fund. We thank Genentech for generously providing omalizumab for the clinical trial.

\section{DISCLOSURE}

The authors declared no conflict of interest.

(C) 2012 Society for Mucosal Immunology

\section{REFERENCES}

1. Noon, L. Prophylactic inoculation for hay fever. Lancet 1, 1572 (1911).

2. Larche, M., Akdis, C.A. \& Valenta, R. Immunological mechanisms of allergen-specific immunotherapy. Nat. Rev. Immunol. 6, 761-771 (2006).

3. Jutel, M. \& Akdis, C.A. Immunological mechanisms of allergen-specific immunotherapy. Allergy 66, 725-732 (2011).

4. Secrist, H., Chelen, C.J., Wen, Y., Marshall, J.D. \& Umetsu, D.T. Allergen immunotherapy decreases interleukin 4 production in CD4+ T cells from allergic individuals. J. Exp. Med. 178, 2123-2130 (1993).

5. Varney, V.A. et al. Influence of grass pollen immunotherapy on cellular infiltration and cytokine mRNA expression during allergen-induced latephase cutaneous responses. J. Clin. Invest. 92, 644-651 (1993).

6. Akdis, C.A., Blesken, T., Akdis, M., Wuthrich, B. \& Blaser, K. Role of interleukin 10 in specific immunotherapy. J. Clin. Invest. 102, 98-106 (1998). 
7. Meiler, F., Zumkehr, J., Klunker, S., Ruckert, B., Akdis, C.A. \& Akdis, M. In vivo switch to IL-10-secreting T regulatory cells in high dose allergen exposure. J. Exp. Med. 205, 2887-2898 (2008).

8. Weiner, H.L. Oral tolerance for the treatment of autoimmune diseases. Ann. Rev. Med. 48, 341-351 (1997).

9. de Jong, E.C., Spanhaak, S., Martens, B.P., Kapsenberg, M.L., Penninks, A.H. \& Wierenga, E.A. Food allergen (peanut)-specific TH2 clones generated from the peripheral blood of a patient with peanut allergy. J. Allergy. Clin. Immunol. 98, 73-81 (1996).

10. Higgins, J.A., Lamb, J.R., Lake, R.A. \& O’Hehir, R.E. Polyclonal and clonal analysis of human CD4+ T-lymphocyte responses to nut extracts. Immunology 84, 91-97 (1995).

11. Dorion, B.J. et al. The production of interferon-gamma in response to a major peanut allergy, Ara h II correlates with serum levels of IgE anti-Ara h II. J. Allergy Clin. Immunol. 93, 93-99 (1994).

12. Turcanu, V., Maleki, S.J. \& Lack, G. Characterization of lymphocyte responses to peanuts in normal children, peanut-allergic children, and allergic children who acquired tolerance to peanuts. J. Clin. Invest. 111, 1065-1072 (2003).

13. Shreffler, W.G., Wanich, N., Moloney, M., Nowak-Wegrzyn, A. \& Sampson, H.A. Association of allergen-specific regulatory T cells with the onset of clinical tolerance to milk protein. J. Allergy. Clin. Immunol. 123, 43-52.e7 (2009).

14. Pajno, G.B. et al. Oral immunotherapy for cow's milk allergy with a weekly up-dosing regimen: a randomized single-blind controlled study. Ann. Allergy Asthma Immunol. 105, 376-381 (2010).

15. Buchanan, A.D. et al. Egg oral immunotherapy in nonanaphylactic children with egg allergy. J. Allergy Clin. Immunol. 119, 199-205 (2007).

16. Nash, S. et al. Oral peanut immunotherapy for children with peanut allergy. J. Allergy Clin. Immunol. 121, S147 (2008).

17. Hofmann, A.M. et al. Safety of a peanut oral immunotherapy protocol in children with peanut allergy. J. Allergy. Clin. Immunol. 124, 286-291, 291. e1-6 (2009).

18. Blumchen, K. et al. Oral peanut immunotherapy in children with peanut anaphylaxis. J. Allergy Clin. Immunol. 126, 83-91.e1 (2010).

19. Nadeau, K., Schneider, L., Hoyte, E., Borras, I. \& Umetsu, D. Rapid oral desensitization in combination with omalizumab therapy in patients with cow's milk allergy. J. Allergy Clin. Immunol. 127, 1722-1724 (2011).

20. Faria, A.M. \& Weiner, H.L. Oral tolerance. Immunol. Rev. 206, 232-259 (2005).

21. Hatachi, S. et al. CD4+ PD-1+ T cells accumulate as unique anergic cells in rheumatoid arthritis synovial fluid. J. Rheumatol. 30, 1410-1419 (2003).

22. Sharpe, A.H., Wherry, E.J., Ahmed, R. \& Freeman, G.J. The function of programmed cell death 1 and its ligands in regulating autoimmunity and infection. Nat. Immunol. 8, 239-245 (2007).

23. Sicherer, S.H. \& Sampson, H.A. 9. Food allergy. J. Allergy Clin. Immunol 117, S470-S475 (2006).

24. Boyce, J.A. et al. Guidelines for the diagnosis and management of food allergy in the United States: summary of the NIAID-sponsored expert panel report. J. Allergy Clin. Immunol. 126, 1105-1118 (2010).

25. Sicherer, S.H. \& Sampson, H.A. Food allergy. J. Allergy Clin. Immunol. 125, S116-S125 (2010)

26. Meglio, P., Bartone, E., Plantamura, M., Arabito, E. \& Giampietro, P.G. A protocol for oral desensitization in children with lgE-mediated cow's milk allergy. Allergy 59, 980-987 (2004).

27. Longo, G. et al. Specific oral tolerance induction in children with very severe cow's milk-induced reactions. J. Allergy Clin. Immunol. 121, 343-347 (2008).

28. Staden, U. et al. Rush oral immunotherapy in children with persistent cow's milk allergy. J. Allergy Clin. Immunol. 122, 418-419 (2008).

29. Clark, A.T., Islam, S., King, Y., Deighton, J., Anagnostou, K. \& Ewan, P.W. Successful oral tolerance induction in severe peanut allergy. Allergy 64, 1218-1220 (2009).
30. Enrique, E. et al. Sublingual immunotherapy for hazelnut food allergy: a randomized, double-blind, placebo-controlled study with a standardized hazelnut extract. J. Allergy Clin. Immunol. 116 1073-1079 (2005).

31. Skripak, J.M., Matsui, E.C., Mudd, K. \& Wood, R.A. The natural history of IgE-mediated cow's milk allergy. J. Allergy Clin. Immunol. 120, 1172-1177 (2007).

32. Francis, J., Till, S. \& Durham, S. Induction of IL-10+CD4+CD25+ T cells by grass pollen immunotherapy. J. Allergy Clin. Immunol. 111, 1255-1261 (2003).

33. Oldfield, W., Larche, M. \& Kay, A. Effect of T-cell peptides derived from Fel $d 1$ on allergic reactions and cytokine production in patients sensitive to cats: a randomised controlled trial. Lancet 360, 47-53 (2002).

34. Verhoef, A., Alexander, C., Kay, A.B. \& Larche, M. T cell epitope immunotherapy induces a CD4+ T cell population with regulatory activity. PLoS Med. 2, e78 (2005)

35. Aslam, A., Chan, H., Warrell, D.A., Misbah, S. \& Ogg, G.S. Tracking antigen-specific T-cells during clinical tolerance induction in humans. PLOS ONE 5, e11028 (2010).

36. Sakaguchi, S., Miyara, M., Costantino, C.M. \& Hafler, D.A. FOXP3+ regulatory T cells in the human immune system. Nat. Rev. Immunol. 10, 490-500 (2010).

37. Varshney, P. et al. A randomized controlled study of peanut oral immunotherapy: clinical desensitization and modulation of the allergic response. J. Allergy Clin. Immunol. 127, 654-660 (2011).

38. Jones, S.M. et al. Clinical efficacy and immune regulation with peanut oral immunotherapy. J. Allergy Clin. Immunol. 124, 292-300e1-97 (2009).

39. Mori, F., Bianchi, L., Pucci, N., Azzari, C., De Martino, M. \& Novembre, E. CD4+CD25+Foxp3+ T regulatory cells are not involved in oral desensitization. Int. J. Immunopathol. Pharmacol. 23, 359-361 (2010).

40. Kim, E.H. et al. Sublingual immunotherapy for peanut allergy: clinical and immunologic evidence of desensitization. J. Allergy Clin. Immunol. 127, 640-646.e1 (2011)

41. Tiemessen, M.M., Van Hoffen, E., Knulst, A.C., Van Der Zee, J.A., Knol, E.F. \& Taams, L.S. CD4 CD25 regulatory T cells are not functionally impaired in adult patients with IgE-mediated cow's milk allergy. J. Allergy. Clin. Immunol. 110, 934-936 (2002)

42. Nagata, S. et al. Human Peyer's patch T cells are sensitized to dietary antigen and display a Th cell type 1 cytokine profile. J. Immunol. 165, 5315-5321 (2000)

43. Stock, $\mathrm{P}$. et al. CD8(+) T cells regulate immune responses in a murine model of allergen-induced sensitization and airway inflammation. Eur. J. Immunol. 34, 1817-1827 (2004).

44. Dominguez-Villar, M., Baecher-Allan, C.M. \& Hafler, D.A. Identification of Thelper type 1-like, Foxp3(+) regulatory T cells in human autoimmune disease. Nat. Med. 17, 673-675 (2011).

45. Scurlock, A.M., Vickery, B.P., Hourihane, J.O. \& Burks, A.W. Pediatric food allergy and mucosal tolerance. Mucosal. Immunol. 3, 345-354 (2010).

46. van Halteren, H.K., van der Linden, P.W., Burgers, J.A. \& Bartelink, A.K. Discontinuation of yellow jacket venom immunotherapy: follow-up of 75 patients by means of deliberate sting challenge. J. Allergy Clin. Immunol. 100, 767-770 (1997).

47. Cox, L. \& Cohn, J.R. Duration of allergen immunotherapy in respiratory allergy: when is enough, enough? Ann. Allergy Asthma Immunol. 98, 416-426 (2007).

48. Varshney, P. et al. Peanut Oral Immunotherapy (OIT) induces immunologic changes supporting the development of tolerance. J. Allergy Clin. Immunol. 125, AB59 (Abstract) (2010).

49. Gernez, Y. et al. Basophil CD203c levels are increased at baseline and can be used to monitor omalizumab treatment in subjects with nut allergy. Int. Arch. Allergy Immunol. 154, 318-327 (2010). 